\title{
Correction to: Advanced Robotic Therapy Integrated Centers (ARTIC): an international collaboration facilitating the application of rehabilitation technologies
}

Hubertus J. A. van Hedel ${ }^{1 *}$, Giacomo Severini ${ }^{2,3}$, A. Scarton ${ }^{2}$, A. O'Brien², T. Reed ${ }^{4}$, D. Gaebler-Spira ${ }^{5}$, T. Egan ${ }^{5}$, A. Meyer-Heim', J. Graser ${ }^{6}$, K. Chua ${ }^{7}$, D. Zutter ${ }^{8}$, R. Schweinfurther ${ }^{8}$, J. C. Möller ${ }^{8}$, Liliana P. Paredes ${ }^{8}$, A. Esquenazi ${ }^{9}$, S. Berweck ${ }^{10}$, S. Schroeder ${ }^{11}$, B. Warken ${ }^{11}$, A. Chan ${ }^{12}$, A. Devers ${ }^{12}$, J. Petioky ${ }^{13}$, Nam-Jong Paik ${ }^{14}$, W. S. Kim ${ }^{14}$,

P. Bonato ${ }^{2}$, M. Boninger ${ }^{15}$ and ARTIC network

\section{Correction}

The original article [1] contains a small mistake concerning the ARTIC Team members mentioned in the Acknowledgements. The team member, Rocco Salvatore Calabrò had their name presented incorrectly. This has now been corrected in the original article.

\footnotetext{
Author details

'Rehabilitation Center for Children and Adolescents, University Children's Hospital Zurich, Mühlebergstrasse 104, CH-8910 Affoltern am Albis, Switzerland. ${ }^{2}$ Department of Physical Medicine and Rehabilitation, Harvard Medical School, at Spaulding Rehabilitation Hospital, Charlestown, MA, USA. ${ }^{3}$ University College Dublin, Dublin, Ireland. ${ }^{4}$ Acute Neurological Rehabilitation Unit, Wellington Hospital, London, UK. ${ }^{5}$ Shirley Ryan AbilityLab, Chicago, USA. ${ }^{6}$ Rehabilitation Center for Children and Adolescents, University Children's Hospital Zurich, Mühlebergstrasse 104, CH-8910 Affoltern am Albis, Switzerland. 'Tan Tock Seng Hospital Rehabilitation Centre, Singapore, Republic of Singapore. ${ }^{8}$ Rehaklinik Zihlschlacht, Center for Neurological Rehabilitation, Zihlschlacht, Switzerland. ${ }^{9}$ Department of Physical Medicine and Rehabilitation, MossRehab, Philadelphia, USA. ${ }^{10} \mathrm{Clinic}$ for Neuropediatrics and Neurological Rehabilitation, Epilepsy center for children and adolescents, Schön Klinik Vogtareuth, Vogtareuth, Germany. ${ }^{11}$ Paediatric Neurology, Developmental Medicine and Social Paediatrics, Ludwig Maximilian University, Hauner Children's Hospital, Munich, Germany. ${ }^{12}$ Sheltering Arms Physical Rehabilitation Center, Richmond, USA. ${ }^{13}$ Rehabilitation Centre Kladruby, Kladruby, Czech Republic. ${ }^{14}$ Department of Rehabilitation Medicine, Seoul National University Bundang Hospital, Seongnam, Republic of Korea. ${ }^{15}$ Department of Physical Medicine and Rehabilitation, University of Pittsburgh and VA Pittsburgh Health Care System, Pittsburgh, USA.
}

Received: 19 April 2018 Accepted: 19 April 2018 Published online: 08 May 2018

\section{Reference}

1. Van Hedel HJA, et al. Advanced Robotic Therapy Integrated Centers (ARTIC): an international collaboration facilitating the application of rehabilitation technologies. J Neuroeng Rehabil. 2018;15:30.

\footnotetext{
* Correspondence: hubertus.vanhedel@kispi.uzh.ch

'Rehabilitation Center for Children and Adolescents, University Children's Hospital Zurich, Mühlebergstrasse 104, CH-8910 Affoltern am Albis, Switzerland
}

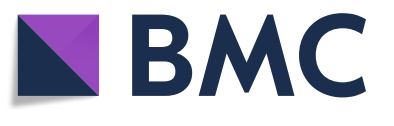

(C) The Author(s). 2018 Open Access This article is distributed under the terms of the Creative Commons Attribution 4.0 International License (http://creativecommons.org/licenses/by/4.0/), which permits unrestricted use, distribution, and reproduction in any medium, provided you give appropriate credit to the original author(s) and the source, provide a link to the Creative Commons license, and indicate if changes were made. The Creative Commons Public Domain Dedication waiver (http://creativecommons.org/publicdomain/zero/1.0/) applies to the data made available in this article, unless otherwise stated. 